\title{
Bulk Simulation Data in Programming Class
}

\author{
Tana Kraikruan \\ Training Center of Green Cyber Advance Co., Ltd., Bangkok, Thailand \\ Email: tana@gca.co.th
}

Received July 2013

\begin{abstract}
This paper discusses a few issues related to Development of Learning Environment to solve problems that are commonly found from IT graduated students from college and university, which cannot solve and manage mega transaction of database from reality business.
\end{abstract}

Keywords: Development of Learning Environment; Teaching Improvement; Database Management; Teaching Environment; Teaching in Information Technology; Computer Lab Improvement

\section{Introduction}

In real business database will contain a million transactions Most companies have their own database server. Some of them have storage area network that needs quality and experience recruitment. The problem is that most colleges and universities focus agenda on programming skill and teach students to install both compiler and database in the same computer that is well known like "localhost database", which means graduated student never face with mega database and don't know the best practice to manage to be successful in business.

\section{Problem Motivation}

\section{Computer Training Room Environment}

When we are teaching student in programing class, after basic lesson we teach them to create database and write program connecting database to manage database like to add, to edit and to delete records. We found that almost student computers have all in one virtual server program that is already installed and ready to use in a limit of PC hard disk size. We teach them to connect server and almost use "localhost" or "127.0.0.1" that means connecting to own a PC like virtual database server (in Figure 1).

Almost computer labs do not own centralized database facilities.

\section{Recruitment Experience Resume}

New graduated students will face with experience required due to recruitment company must define successful recruitment consultant for 3rd party human resource department.

Almost all the resumes from new graduated students will have only one programming language that they have been learning from university or school. They cannot refer to experience from computer lab room as it cannot guarantee anything.

\section{Business Database Server}

In real business, a data center has various of database servers and the size will be larger than that of the usual PC hard disk. Some companies use San Storage that has more than a million transactions that new graduated students never have expe- rienced.

Server farm as shown in Figure $\mathbf{2}$ is a collection of computer servers which are usually maintained by an enterprise to accomplish server needs far beyond the capability of one machine. Almost have SAN Stolage with Terabyte capacity.

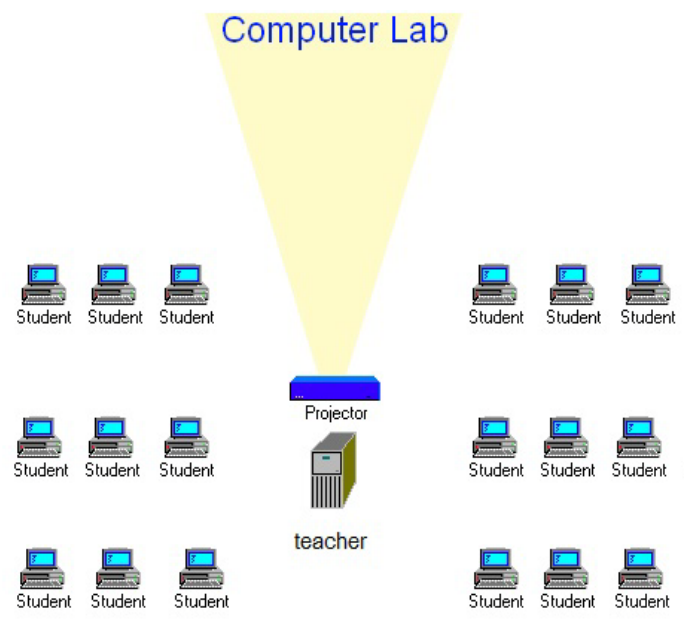

Figure 1.

Computer lap in almost school and university.

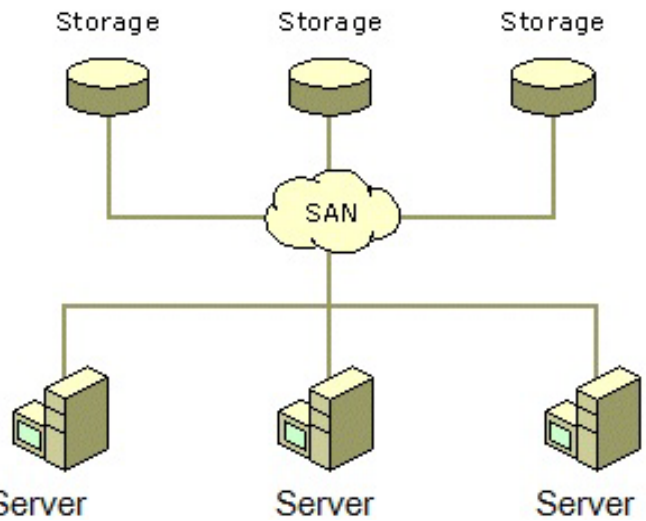

Figure 2.

Sample of database farm in business company. 


\section{Methodologies}

\section{Define Standard of Environment for Lab}

- Database server with terabyte hard drive.

- DBMS for Server edition.

- $\quad$ SOAP for XML request XML (Tang, 2009), request teaching resource platform.

- Virtual machine (Saxena \& Kumar, 2012), representation of an object-oriented UML database on hand-held devices.

\section{Define Sample Bulk Simulation Data}

- Sample database in various database format.

- Various sizes of data transaction simulation.

- Database backup.

- Disaster simulation.

- Financial and tax database.

\section{Define Network Infrastructure for Computer Lab}

We can use the old server to make virtual database server using VMWARE or Open Source Software to import transaction and Various of OS server type like SOAP, Linux and Windows.

The new infrastructure (in Figure 3) will not affect budget due to we focus on data more than hardware. In 2013, Computer hard-disk in a market almost has over 500 GB capacity that can install and dump simulation data more than 100,000,000 records.

Sample Customer Database as shown in Figure 4, captures from the CRM department will show that a million of transactions can run on Virtual Server and use only 193 MB.

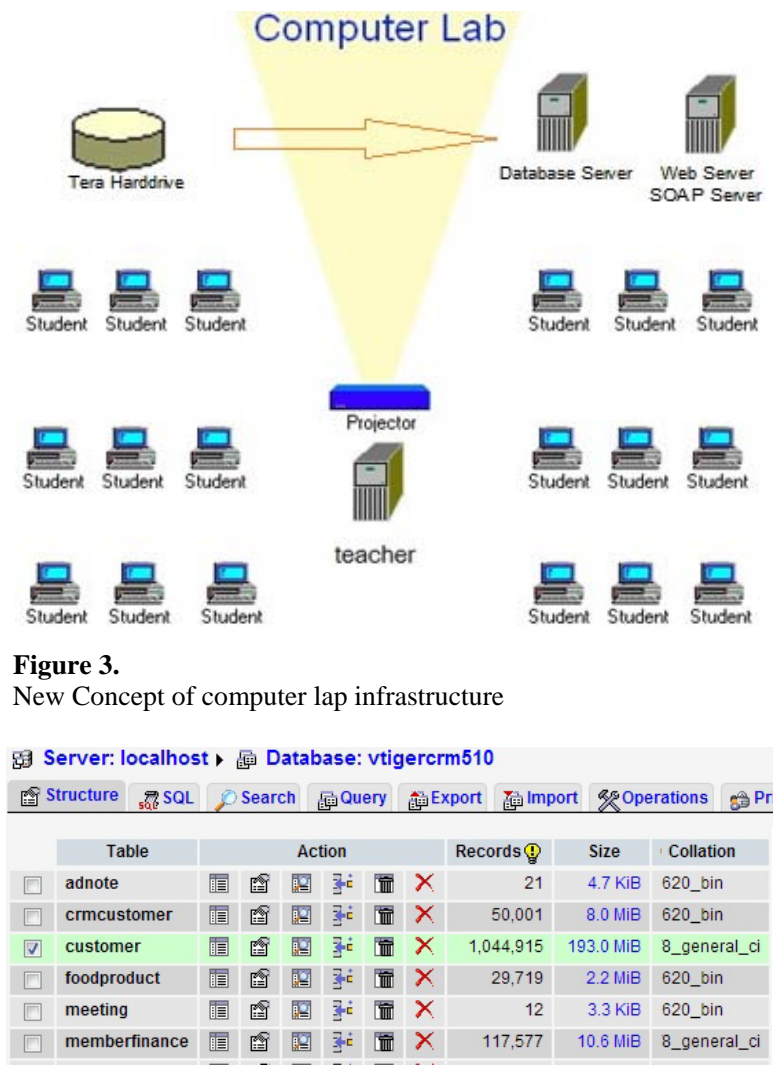

Figure 4.

MySQL transaction 1,044,915 records/size 193 MB.

\section{The Key Performance Indicator Evaluation Process}

Aims

- Database skill improvement (Gao, Coldwell-Neilson, \& Goscinski, 2013) represent to Improving Teaching.

- Quantitative and qualitative consultant, SQL programming code evaluation.

- Identification and commendation of exceptional performance

- Timely identification of issues and resolution during the database query process

- Understanding the Basics of Business.

New Concept of Computer Lap Infrastructure will make teamwork and relationship between students in the classroom work together with the same database and facilities like virtual office.

Students (in Figure 5) can work together to join relationship database by using Various of SQL query command proposed a novel approach to the information content of data in a database (Feng \& Salt, 2010).

SQL server supports bulk exporting and importing using SQL command as refer from MSDN (Wang, Wang, Liang, \& Xiao, 2010), Computer Assisted Instruction as shown in Figure 6.

\section{Key Elements for Teamwork Evaluation Process}

- Agreement on project key performance indicator goal of project.

- Quarterly key performance indicator evaluation of project team members.

- In project key performance indicator evaluation at project gateways.

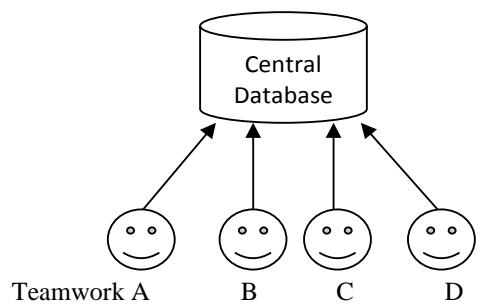

Figure 5.

Student A-D join a project in the classroom.

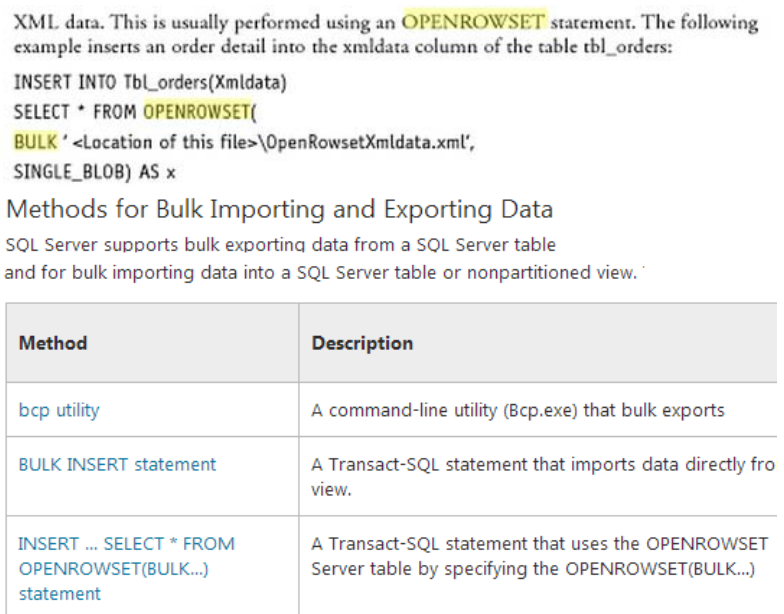

Figure 6.

Methods for bulk data for examination (MSDN). 


\section{T. KRAIKRUAN}

- Post project evaluation of key performance indicators against agreed targets.

\section{Evaluating Examination}

After renovation computer lab, teachers can evaluate both programming skills and business skills. Students will have experience with bulk with simulation data and must solve the problem like disaster with financial database. The examination will cover logic and skills.

\section{Conclusion}

Database server with data simulation database is very important to help students to meet the real experience with business database. Server and Data transaction environment are one important option to upgrade learning system in IT area education.

Simulations will help students to have experience and can solve a variety of problems. Experience will help students to have better opportunities in recruitment.

\section{REFERENCES}

Tang, S. (2009). Sharing and implementation of heterogeneous data- base for education resource based on XML. Journal of Software Engineering and Applications, 2, 200-205. http://dx.doi.org/10.4236/jsea.2009.23027

Saxena, V., \& Kumar, S. (2012). Object-oriented database connectivity for hand held devices. Journal of Software Engineering and Applications, 5, 314-320. http://dx.doi.org/10.4236/jsea.2012.55037

Gao, S., Coldwell-Neilson, J., \& Goscinski, A. (2013). Approaches to improving teaching. Creative Education, 4, 1-7. http://dx.doi.org/10.4236/ce.2013.47A2001

Feng, J., \& Salt, D. (2010). Information content inclusion relation and its use in database queries. Journal of Software Engineering and Applications, 3, 255-267. http://dx.doi.org/10.4236/jsea.2010.33031

Wang, L., Wang, X., Liang, N., \& Xiao, M. (2010). How to make highly rational use of modern educational technologies. Intelligent Information Management, 2, 647-651.

http://dx.doi.org/10.4236/iim.2010.211074 